\title{
FROM FOLK TO POPULAR: THE EVOLUTION AND DIFFUSION OF TRUCK ART IN PAKISTAN INTO MAINSTREAM CULTURE THROUGH FASHION INDUSTRY
}

\author{
Sana Munir Kazmi \\ $\mathrm{PhD}$ Scholar, Taxila Institute of Asian Civilizations \\ Quaid-i-Azam University Islamabad \\ Ghani-ur-Rahman \\ Professor, Taxila Institute of Asian Civilizations \\ Quaid-i-Azam University Islamabad \\ ghani@qau.edu.pk
}

\begin{abstract}
In this study an analysis is carried out of how Truck Art- an indigenous art form of Pakistan, made its way to popular culture in the form of decorative motifs and items being used in fashion, clothes, and other décor items. The diffusion of truck art into day to day objects can be seen as a cultural shift where one form of art gains popularity by masses to be incorporated in other objects to be enjoyed by masses. This research deals with aesthetic representation of outfitters decorated with truck art styles by focusing on how such styles and articulation of cultural aesthetics add to them in everyday lives. Using a purposive sampling technique, this research gathered data from fashion designers and owners of different apparel brands to explore the motivation and reasons of truck art diffusion. This research illuminates the fact that truck art is not only a form of art, but it also is a platform for the depiction of one's cultural heritage; hence it has gained popularity not only among artists but also amongst the general public. Thus, this art form flourished and gained popularity amongst masses through its portrayals in different fashion and other consumer items. The study implies that art can be used as a strong medium to bring a change in the society because of its strong influence, and at the same time it can be used to promote cultural industries of Pakistan at global level.
\end{abstract}

Keywords: Fashion, truck art, fashion industry, visual culture, Pakistan.

\section{INTRODUCTION}

In the words of Elias (2005), Pakistani trucks act as an adornment of the roads by transforming the landscape into "a checkerboard of moving religious and cultural tableaus" (p. 124). Every little adornment on the truck has special significance and meaning for the truck driver and owner. Art is a social product suggesting that human sensibilities are created and cultivated through social history and interactions. It omits the irrelevant details of reality and gives colors and life to the significant details to portray real as the ideal. It provides a unique perspective, a fresh view towards life and society which is not apparent otherwise. It brightens the life by touching upon emotions and feelings in a surprising and subtle manner.

In recent years, art is defined more broadly, which has lent to the growing recognition of its involvement in influencing the society by not just highlighting and solving social problems; but also improving the quality of life by enriching human life. This is why, fostering creativity and art is a part of all societies across the globe. In developing countries like Pakistan, however, preservation and proliferation of art has been done, not through organized efforts, but through fragmented factions of the society in order to commoditize the art. Current literature in the field of consumer behavior reveals that with increasing commercial influence on the popular culture, arts and aesthetics are making their way into everyday lives. Studies on various consumer related areas including fashion, visual images, and personal care have begun to elaborate and explain the aesthetic discourse of everyday life. To reiterate, aesthetics offers a wide range of meanings through sensory experiences relating to arts, crafts, performing arts, or other visual forms from day-to-day objects. 
Truck Art, which is one of the popular arts form of Pakistan, is also being commoditized in a number of ways and has diffused into popular culture through fashion and decorative items for mass consumers. Its diffusion into other spheres of lives in the form of decorative items, events and home décor themes, fashion and clothing items, and decorative utensils represent a cross between mass and folk culture, which highlights the importance of art and its effect on cultural evolution. This raises the question about why consumers are motivated to consume an indigenous art and incorporate it into their lifestyle. This study explores this very phenomenon by looking at how truck art has made its way into popular culture to represent the collective identity of the people of Pakistan.

\section{Problem Statement}

Art is an important aspect of culture that needs to be preserved and proliferated, especially in a society where institutional and formal efforts to promote art are limited, but a culture is rife with diversity, other avenues become apparent to promote local culture and art. It is because of the beauty and aesthetic significance of the truck art to the Pakistani culture that truck art is being incorporated in different spheres of life now. From fashion industry to interior decoration, the truck art is making its appearance everywhere. This diffusion of truck art into day to day objects can be seen as a cultural shift where one form of art gains popularity by masses to be incorporated in other objects to be enjoyed by masses. At the same time, it is interesting to explore how a form of art which remained vastly popular among transporters to decorate their vehicles became the part of popular culture that common people want to enjoy and express. This is an interesting anthropological question that will be the focus of this research. In the backdrop of this, the fact that fashion and apparel industry of Pakistan is thriving and growing, the motivation to promote truck art through apparel and fashion is an interesting phenomenon currently happening. However, what inspires designers as well as consumers to adopt such art into fashion is research worthy.

\section{Objectives and Scope of the Study}

The core objective of the study is to document the diffusion of Truck Art into popular culture of Pakistan. More specifically, the research aims to:

1. Explore the motivation behind adoption of truck art themes by masses specifically in the form of fashion and apparel

2. Understand the impact of consumption of truck art by masses on the folk industry in general, and truck art industry in particular

The scope of this study involves anthropological investigation of the diffusion of Truck Art while focusing on urban areas of Pakistan. Mainly, the study involves researching and exploring the influence of Truck Art seen in Islamabad and Karachi to extrapolate the findings.

\section{REVIEW OF LITERATURE}

The intricacies that art exhibits by influencing various facets of human lives, and being influenced by various factors of the environment have been a focus of research for experts belonging to different disciplines. From the earliest paintings in the caves depicting hunters and beasts, to traditional religious paintings aimed at evoking certain behavior among the masses, to architectural edifices showcasing the grandeur of emperors, to the modern day art embracing the free will of humans, art has played a pivotal role not only in reflecting the society, but also in directing the society into new ways of thinking (Foster, 1989).

\section{Art and Society}

Marx (1963) considers art as a social product by suggesting that the senses of a social man are different from a non-social man because human sensibilities are created and cultivated through social history and interactions. Similarly, Dealey and Ward (1907) explain art as a socializing agency while Ross (1897) considers art a major form of social control. Cooley (1966) believes that art has a moral function by saying that art omits the irrelevant details of reality and gives colors and life to the significant details to 
portray real as the ideal. Freud (1943) takes a psychological perspective and explains it as "fantasy providing catharsis"; art and music therapists consider it an efficient approach to treat mental illnesses; and more recent work explains it as a form of play. Child and Siroto (1965) in their cross cultural research reveal that the quality of work of artists and craftsmen converge across different cultures, and hence supporting the universality of art.

With respect to Art's place in the society, it is seen as a key social institution by the sociologists. Its instrumental uses have been many, from being used as a tool for propaganda to a tool for social control. It is used by various facets of the society from political, religious, educational, military, and economic institutions to gain support from the public for their special purposes (Foster, 1989). At the same time, it is also seen as an agent of social change and sometimes as a measure of social change. Sorokin (1962) asserts that each type of art is reflective of a specific culture and type of personality. In recent years, art is defined more broadly, which has lent it to the growing recognition in its involvement in influencing the society by not just highlighting and solving social problems, but also improving the quality of life by enriching human life (Foster, 1989).

Yet, another way of looking at the relationship between art and society is to understand the influence of society on art. The society influences arts in a number of ways including religion, community, and economy. Demographics also play a meaningful role in shaping a society's preference of arts. For example, a society with ageing population might prefer traditional art, while one with younger population will support popular art forms (Foster, 1989). Art and artistic styles vary with the changes in society and culture. Wood (1993) notes that the differences in artistic styles are more prominent when looking through cultural conditions particular to that time. Foster (1989) notes that art has played a very important role over the last few decades in promoting and highlighting different social issues and problems. In the Western world, for instance, art was extensively used in the form of paintings, literature, music, and folk art to support equal rights for Blacks (Foster, 1989). This brought the popular or pop art into the limelight whereby academics and theorists starting seeing pop art as equally important as the fine arts because of its influence on the society. A popular art, which is the art of the working class, has enabled the blurring of the line between fine arts and folk arts.

\section{Consumption and Commercialization of Art}

Recent literature in the field of consumer behavior reveals that with increasing commercial influence on the popular culture, arts and aesthetics are making their way into everyday lives (Brown and Patterson, 2000; Schroeder, 2005). Studies on various consumer related areas including fashion, visual images, and personal care have begun to find out and explain the aesthetic discourse of everyday life. To reiterate, aesthetics offers a wide range of meanings ranging from sensory experiences relating to arts, crafts, performing arts, or other visual forms (Schroeder and Borgensen, 2002) to sensory experiences relating to day to day objects. Carroll (2001) asserts that it involves a wide array of conceptual categories from art to expression, symbolism, harmony, imagery, beauty, and feelings.

The truck art can be considered a product of a community culture that practices and values the importance of visuals, images, and paintings to present and communicate a public face of the society (Schulze, 2012). This form of moving art can be seen as a form of visual language, a form of expressive communication, and it reflects various religious, mythical, cultural, social, political, and folk themes. This form of art can be classified as a folk art in its true essence because of the fact that it originated amongst a small societal group to represent the traditions, emotions, and beliefs of truck drivers who belong to small rural communities and low income class. However, with the passage of time it started overlapping with the popular culture and popular art to combine the characteristics of both, folk and popular themes.

Its diffusion into other spheres of lives in the form of decorative items, event and home décor themes, fashion and clothing items, and decorative utensils represent a cross between mass and folk culture, which highlights the importance of art and its effect on cultural evolution.

\section{Diffusion of Truck Art}


The rationale of discussing the consumer side of the theory here is to explore the motivation of consuming cultural and artistic products by people. Heilbrun (2002) argues that everyday objects have the potential to fulfil aesthetic needs of consumers by providing sensory experiences in one form or the other. For instance, consumers engage in experiential type products to derive pleasure (for example going to an amusement park, or a resort, or a movie). Similarly, hedonic experience is one whereby consumers derive enjoyment or pleasure through multisensory aspects of the product or experience (Holbrook and Hirschman, 1982). Art consumption can be explained using these experiential and hedonic theories. Individuals exhibit certain consumption behaviors by collecting the past meanings, negotiating future meanings, and assembling the present meanings of various cultural and religious constructs (Venkatesh and Meamber, 2008).

Thus, research on consumer behavior has shown that consumers look for hedonistic experiences by consuming a product, which can explain why art and popular culture makes its way into everyday life of individuals. Rantala and Lehtonen (2001) point out that aesthetics is reflected in the shopping experiences of people as people want to buy things that offer style. Thus, consumption of every object like clothing or home decoration has an aesthetic aspect to it.

\section{Benefits of Truck Art}

According to the analysis by Elias (2003), there is no apparent direct economic benefit of painting and decorating the trucks in current times, yet almost all the trucks on the roads are decorated immensely. When looking at the primary motivation to get the trucks painted, one must look somewhere else than the economic aspect. The motifs and patterns drawn on trucks not only depict aesthetic considerations, but also reveal religious and emotional worldviews of the truck driver and truck painter (Elias, 2003). Truck art is a representation of beauty over legality and practicality. What this means is that a lot of decorations on these moving vehicles depict controversial, illegal, or fictitious drawings. It serves as a source of expression in a country where religious and cultural boundaries are very strict. Some of the motivational factors and reasons behind truck decorations are Killing Boredom on the Road and Bringing Good Fortune and representing the idealism of artist.

\section{Evolution of truck art in Pakistan}

The painting on trucks has its roots going back to the Mughal emperors who used to get their horse carriages decorated with beautiful floral patterns to show royalty and grace (Kurt, 2008). The current form of truck art emerged in the 1940s when Sikh transporters painted their Lorries and vehicles with portraits of their spiritual gurus to safeguard their vehicles from evil eye and mishaps (Paracha, 2016). Muslim transporters, therefore, started painting figures of Sufi saints as a sign of religious devotion and love. Another account of the history of truck art is that competing transporters would paint their trucks with beautiful patterns and designs to catch the eye of the onlookers and as a branding strategy (Kazi, 1998). With the passage of time, and changing influence of the society and environment, political, social, and popular cultural trends started appearing on the trucks too. In 1960s, human portraits were the emerging trend (Paracha, 2016).

\section{Consumer culture and fashion industries}

In early 1960s, the explanations for consumption of fine art and popular art were considered very straightforward. In the pre-industrialized era, fine arts were consumed by the elites because they had the capacity to consume and appreciate it. For the masses though, commercialized popular art met the needs. In this respect, the cultural consumption of art was seen as an activity that was affordable for the elite, and was made affordable to the status seeking masses through commercialization of mass produced art (Lizardo and Skiles, 2008). According to this view, the demand for arts from upper social class as well as masses were met is cultural industry experts who could manipulate the customer preferences. Consumer studies on culture consumption reveal that there is neither an incoherent nor a strict division between the fine and popular culture items (Lizardo and Skiles, 2008). 
Other recent studies have emphasized the significance of social factors in driving the demand for arts. These factors include institutional domains mainly family, work groups, and educational system that forms and influences the cultural consumption patterns (Bourdieu, 1984). Culture industry relies on satisficing rather than rational maximization to produce culture. Similarly, on the demand side, consumption of arts and culture is not a simple determinant of social class divisions, but various factors like education and institutions. Arnold (1883) points out that culture can be used to not only explain how the whole society works through religion, economics, and politics, but also to explain the aesthetic elements of the society through art, music, literature, and drama, etc. With the turn of the $20^{\text {th }}$ century, the rise in industrialization and globalization resulted in emergence of mass cultures and pop culture (Lizardo and Skiles, 2008). According to some philosophers, this led to a rise of culture industry characterized by a one-dimensional society dominated by the likes of Hollywood movies and television that could be used as a political and economic weapon by the elites (Joas, 1992).

It is very important to mention the work of Bourdieu who sought to explain the relationship between culture and social class. One must possess cultural capital which refers to the 'shared high status cultural signals' including attitudes, formal knowledge, and credentials to assess the value of a cultural good (Lamont and Lareau, 1988). Lizardo and Skiles (2008) note that one of the key features of industrialized societies is the organized and formal production of cultural goods and products that existed as a part of folk or community goods. Thus, technological advancements and marketing evolution is also a driver of media cultures, which has had an impact on commodification of the art in recent era. The notion of mass culture when applied to the commercialization of truck art explains one of the reasons why the truck art penetrated and expanded its wings to appear in other areas of Pakistani culture either through fashion, household items, interior decoration, and utensils etc. It is this amalgamation of folk culture into the mass culture to commercialize this art for business purposes, while meeting the needs of masses.

\section{FINDINGS}

While the Truck Art has invaded several areas of popular culture including home and commercial décor, household items (utensils), event themes, and fashion accessories, the most widely appreciated and adopted are in the fashion industry. From high end designers in Pakistan like Maheen Khan and Deepak Perwani to high street brands like Khaadi and Gul Ahmed, motifs and colors of Truck Art have been incorporated in their products like kurtis, shirts, handbags and accessories, and shoes. Similarly, many other popular brands of clothing such as Rangja, Gulabo, Rizwan Baig, Gul Ahmed, Kyseria, Junaid Jamshed (J.), Kapray have introduced their own Truck Art inspired clothing lines in pret wear and casual wear. During survey for this research, some shops including one owned by Hajji Saab at Lok Virsa also showcased artwork presented on small pieces of cloth for decorative purposes. The incorporation of Truck Art inspired designs in clothing by designers led to appreciation of the beauty and uniqueness of this art to masses and many local and small designers also introduced their Truck Art inspired clothing. 

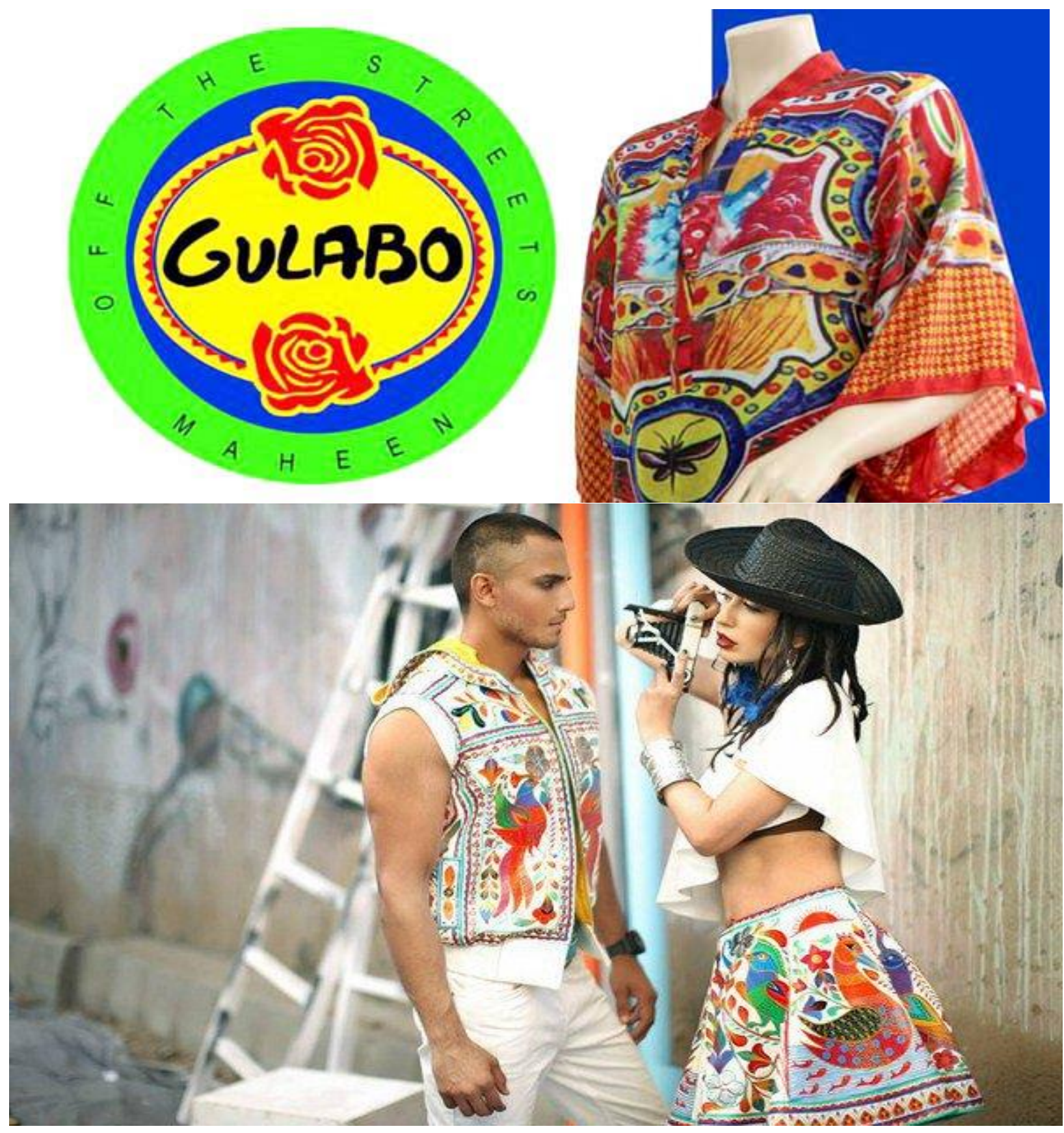
Kazmi \& Rahman

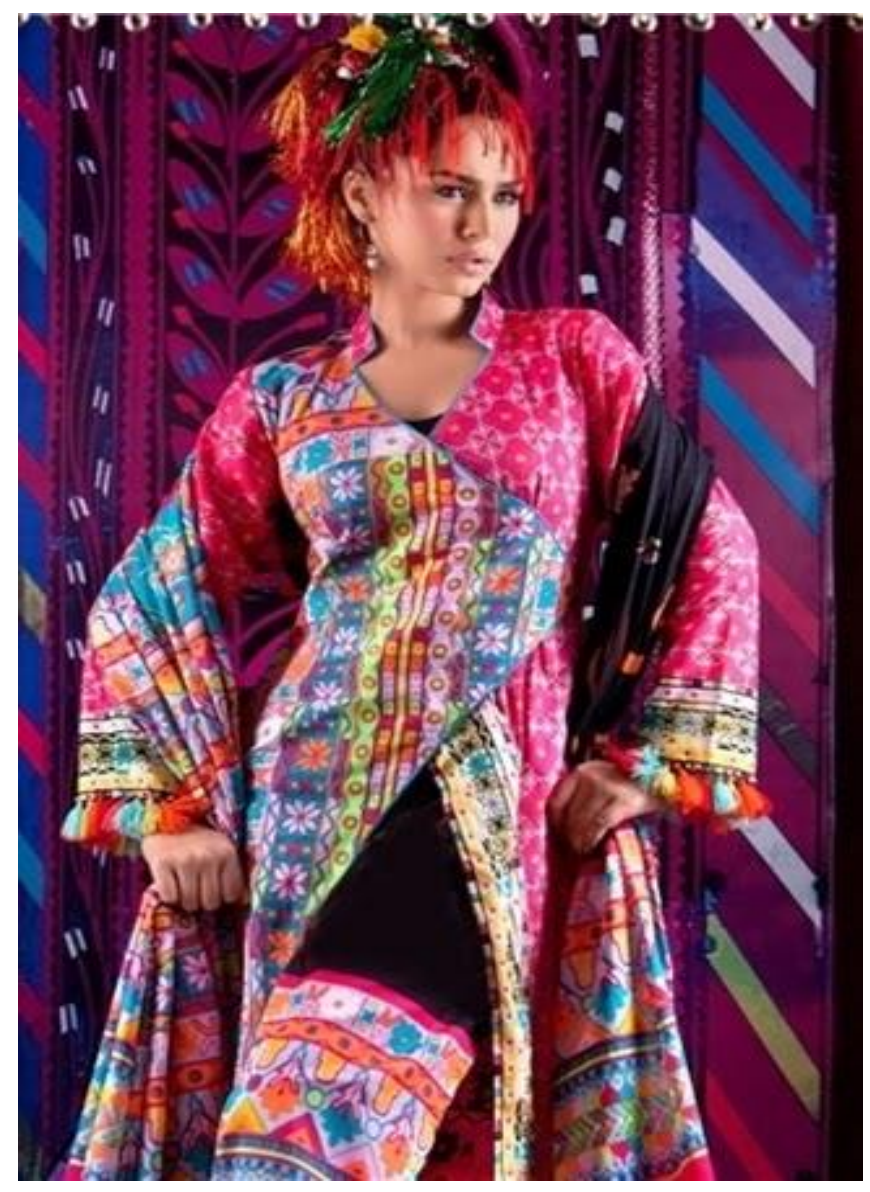




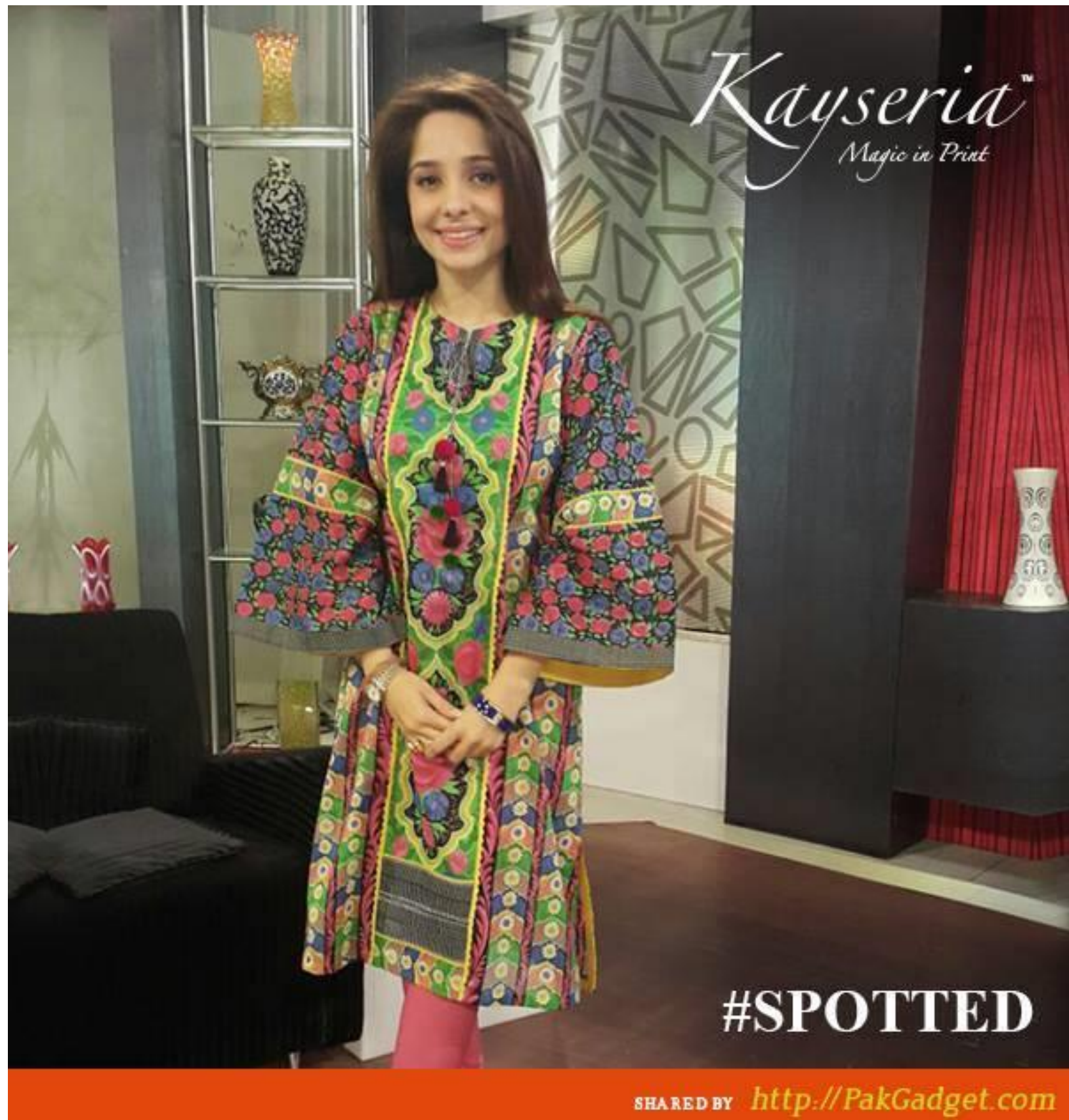

Along with clothing, Truck Art has also made appearance in fashion accessories like handbags, shoes, and wallets. A lot of renowned brand shops of these handbags and wallets including Chapter13, Chinyre by Bareezé, Rangja, Rizwan Baig, Gulabo, and Maheen Hussain amongst many. The work of Chamakpati is more prominent among artisans for hand bags and wallets etc. where they use paper Chamakpati to decorate the pieces.

Similarly, shoes with truck art are also popular amongst youngsters. Shoes of these designs are found to be mainly sold over the internet, however, there are a few branded shops as well as one small local shop in Moti Bazaar, Rawalpindi that sells these unique style of shoes. 


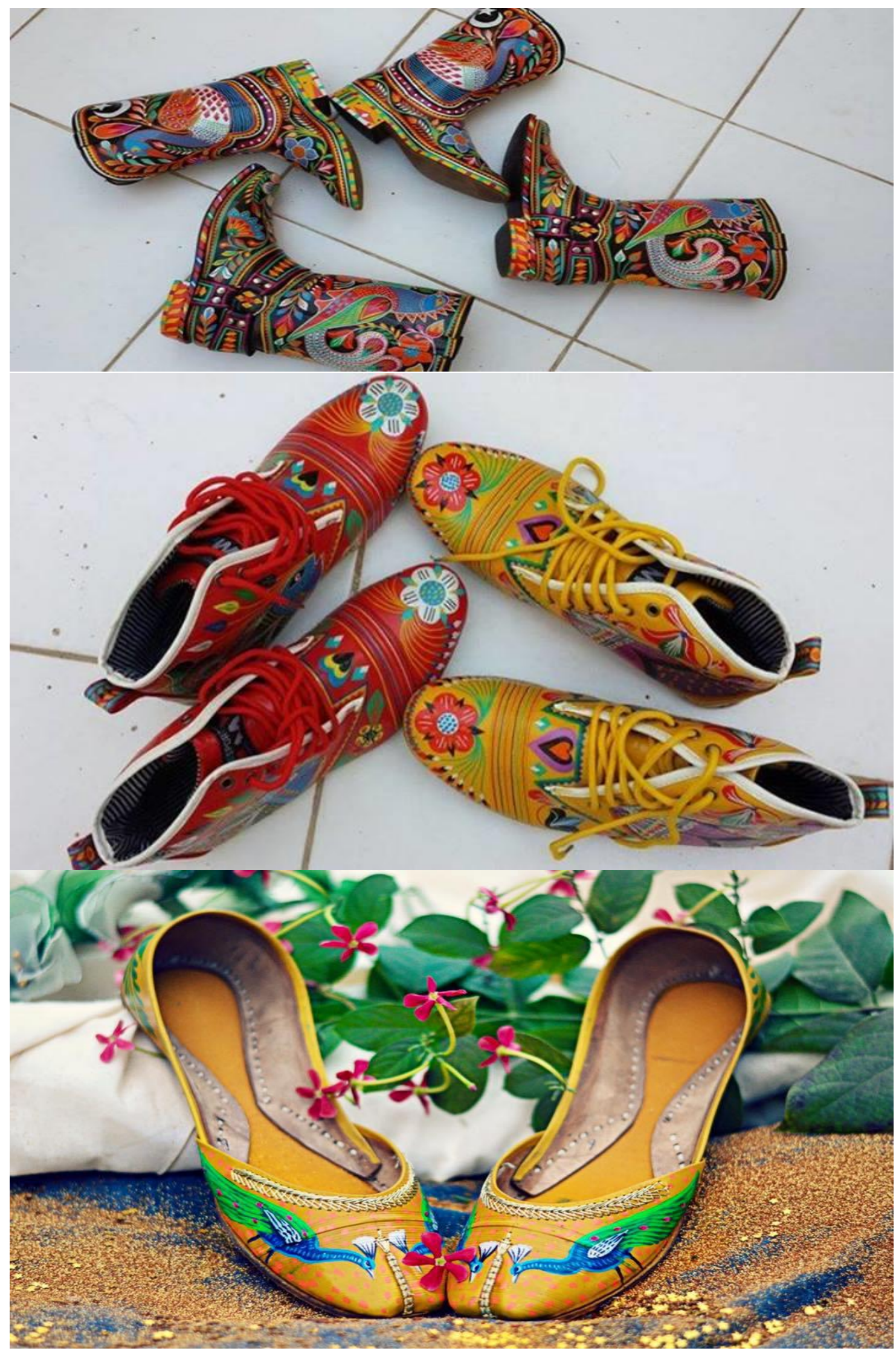




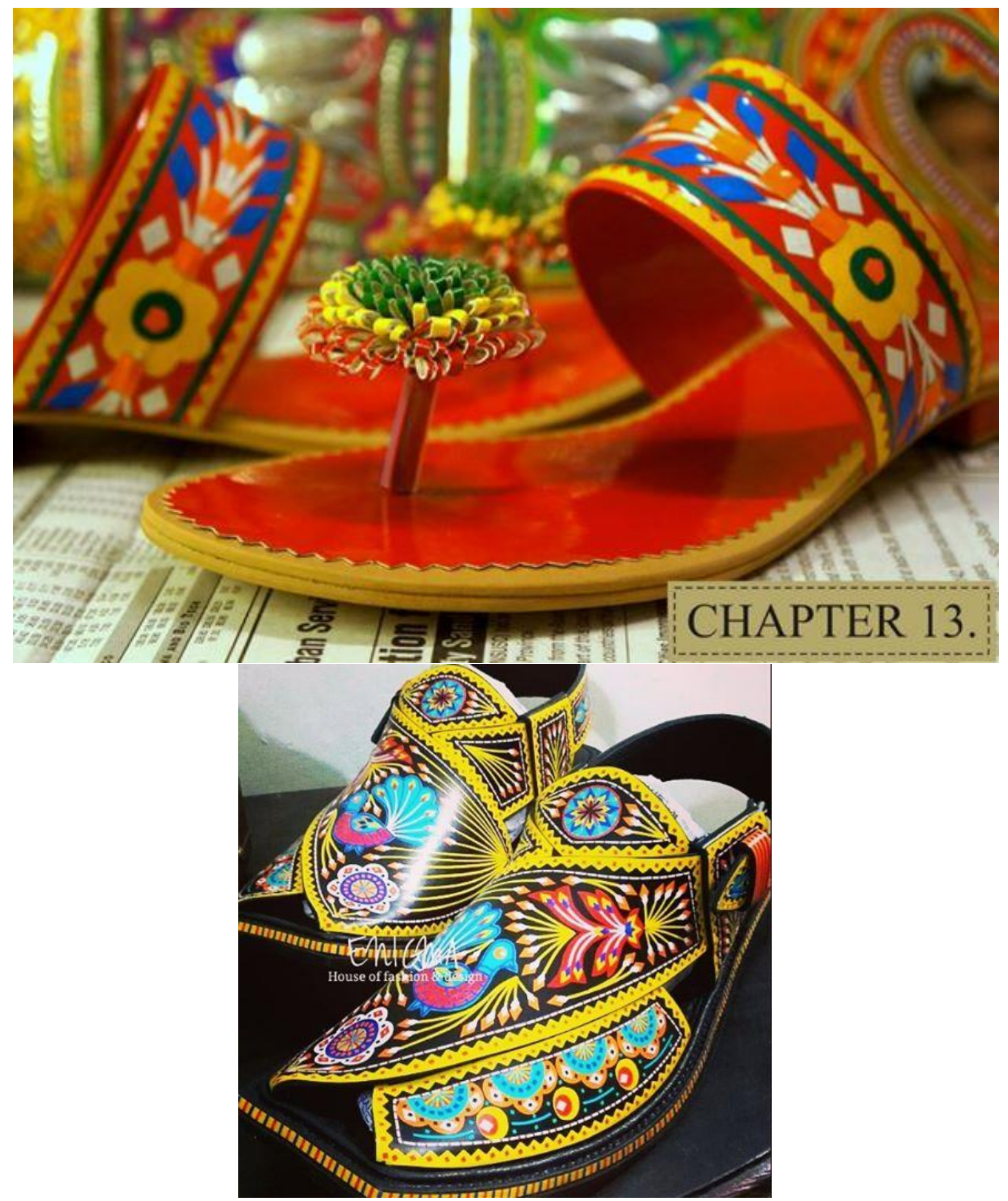




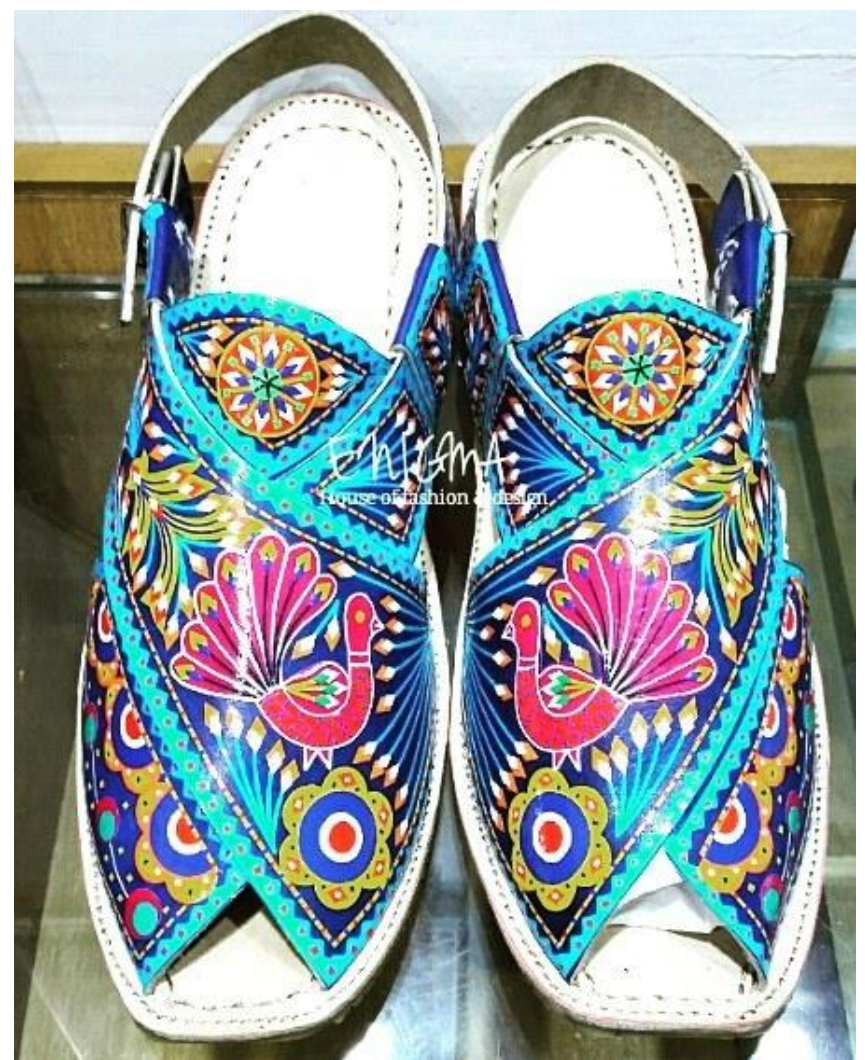

According to an emerging textile designer Ayeza Hussain, who owns an online platform called Basanti for selling her leather products, "I own an online shop of shoes portraying truck art, the prices of these distinctive shoes vary from as low as Rs.1800/- to as high as Rs.2600/- depending upon the amount and quality or the artwork. I have my own template designs of the artwork but if someone does wish to have their own design and colour combination, I try to accommodate their wishes."

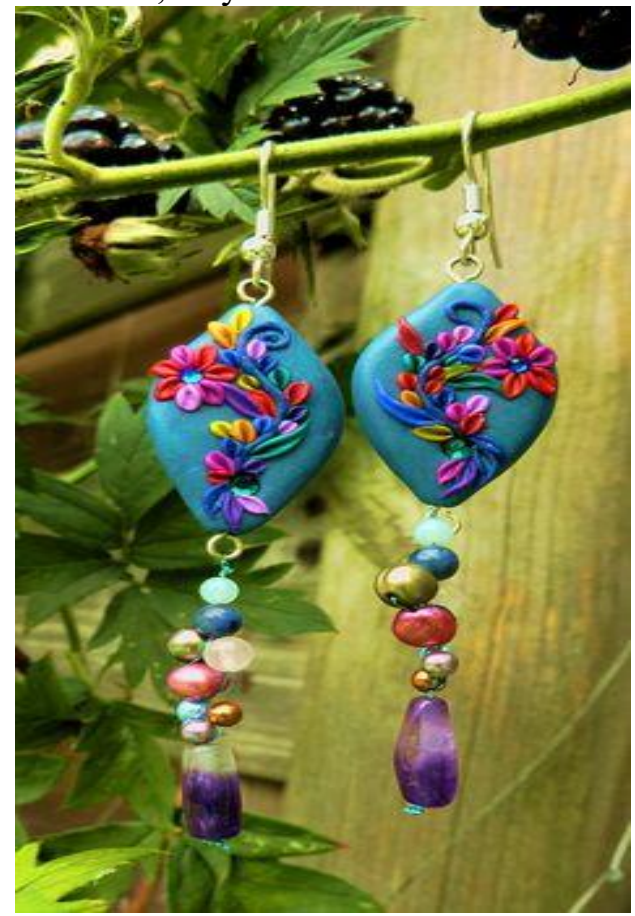



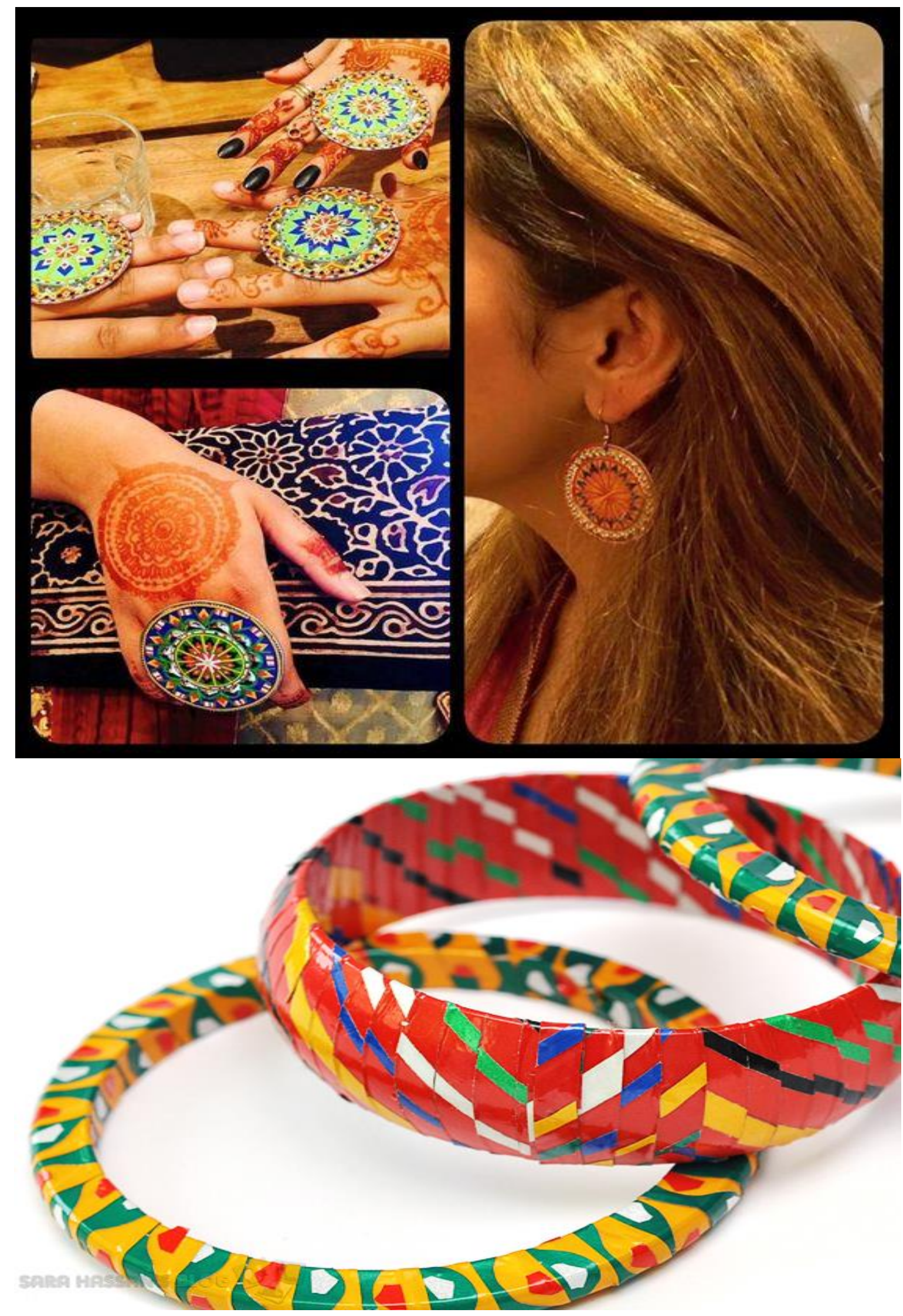
Interviewing owner and the salesperson of the shop at Moti Bazar, who sells shoes with truck art painted designs, he revealed that shop is famous in nearby areas because they only deal in Khusas. They have two designs ,,peacock and a truck on show (front of the Khusa a place is available over fingers for objectification) of the shoe. People do admire the extraordinary work of the artisan on the shoes but still the sales figures of such shoes are low.

\section{DISCUSSION AND ANALYSIS}

Truck Art has become a symbol of pride and popularity for Pakistan even across the Western world owing to the bold and vibrant images it portrays. While it has been argued by the philosophers and anthropologists that art gives a medium of expression to emotions and feelings, which is why humans have used it since the beginning of times. At the same time, consumer theories of the recent times support the idea that individuals consume art in different forms for hedonistic consumption, to experience novelty and creativity, to seek therapeutic value from it, and to immerse themselves in a unique experience (Venkatesh and Meamber, 2008). Both these point of views explain the indulgence of people in cultural heritage and objects related to art. Consumption of art acts as a bridge between individual and cultural identity (Schroeder, 2002).

When applying the philosophical and consumer behavior theories on the gaining popularity of truck art, it can be understood that from its vibrant colors, humorous and witty quips and poetry, detailed decorations, and creative depiction of local political, religious, and popular trends, truck art provides pleasure to the onlookers, and everyone on the highways of Pakistan. Paintings on trucks often challenges the conformity by portraying controversial themes and gives pleasure to those who can $t$ find it in themselves to rebel against the system, but can at least enjoy the diversity of ideas being portrayed on the trucks. This, according to Andel (2015) is an important component of art, that it can evoke feelings by engaging minds and souls through diversity and new perspectives.

An interesting finding of this study has been the fact that truck art themes have been popular amongst not only the middle class population, but also amongst the elites. With major luxury clothing designers adopting the truck art inspired designs, it shows how this art has captivated the attention of the higher socio economic classes. This popularity amongst elites, according to Lizardo and Skiles (2008) can be attributed to the fact that consumption of art does not involve strict segmentation of social class differences. In fact, in an era of technology and mass communication, it is inevitable that art can seep into different social classes relatively easily. This is one of the very important accelerator of diffusion of truck art into various segments of the Pakistani society. Unlike the 18th and 19th century relationship between culture and social classes, where royalties and elites had different cultural consumption patterns than the common man, the rise of the mass culture brings social classes closer, if not economically, then at least through cultural heritage. Various interviews and field observations revealed that people consume items inspired by truck art themes not only for the sake of consuming a unique and artful object, but also to express and show their belongingness and affiliation with Pakistani culture.

The study also showed us that people in general also had contributed a lot in diffusion and profusion of truck art. Regardless of the technological advancements in this modern world, people still are profoundly attached to their culture and are very sensitive in preserving and promoting it. The affection of people to truck art shows their social and moral approach towards their culture. Truck art is considered as the cultural flag carrier amongst general public hence they tend to induce it into their daily life in various forms.

\section{Inspirational Spirits of Truck Art}

Knowing about your own likes and dislikes doesn't a great deal rather know what others will like and admire is within itself an education. This education is what an artist is fully equipped with to present their creativity in the form of their art which is liked and venerated by others too. Hajji Saab, is a prime example of such an artist. He showed his artistic skills using household objects and painting them with fascinating colors and patterns in such a way that one can just not stop admiring the creativity. He is no 
more with us, but his legacy run by his son and son in law in various sites of twin city e.g. Loke Virsa, Arts Council Rawalpindi etc.

Whilst talking with individuals about cultural and historical objects, a respondent who is owner of a café named Naan-Sense in Peshawar, the restaurateur Ms. Laila Habib stated, 'I love cultural objects not because they remind me of our culture, but they inspired me with their patterns of colors and aesthetic understanding of the artists.' People are much more interested to share their understanding about world around them with others and most of the time they use objects rather than words to express their feelings about any particular object, scan or function through fiction and painting it on walls.

Such masterpieces of artwork can be used as decoration of house / restaurants / café and also can serve their daily life purpose to. Amongst several artists who try to express their affection towards truck art by painting various things in that theme there shines a brilliant artist Haider Ali, he is a laudable Karachi based truck artist who tries to explore his love for the art in various techniques. He is widely known by his business named 'Phool Patti'.

Ashfaq Hussain, a truck artist from Carriage Factory, Rawalpindi mentioned that around 5 years ago he painted the graves of parents of his friend on truck art theme. The graves are located nearby 36 Number Graveyard of Peer Wadai area of Rawalpindi.

\section{CONCLUSION}

The findings of this study reveal the motivations and causes of rapidly expanding cultural influence of truck art on the lives of common people of Pakistan. Even in this modern era of technology, culturally enriched truck art has its roots grown deep in the society, let it be the art itself or theme of it induced into any shape or event from dresses to interior/exterior decoration, from key-rings to bikes, from happiness to sorrows in the form of grave painting. This art has carried the folk culture of Pakistan for decades and is continuing to serve the nation by not only preserving the history and culture but also promoting it by inducing into various forms of daily life.

Pakistani Truck art is renowned all over the globe for its use of vibrant colors and imagery that depicts unique artistic taste of the owner. At the same time, it adds a local touch to the vehicle which is manufactured abroad. This art has become the country's cultural identity by showcasing the country as people of creative tastes. Through paintings on the trucks, not only do the truck owners show affiliation with local culture, but also with history, traditions, storytelling, passion, love, religion, politics, poetry, and much more.

While the Truck art has flourished into various domains of the popular culture, the present study has also identified the impact it has on the fashion industry. The impact on fashion industry includes clothing, shoes, jewelry and clothing accessories like wallets and handbags.

\section{REFERENCES}

Arnold, M. (1883). Culture \& anarchy; Friendship's garland (Vol. 2). Macmillan.

Bourdieu, P. (1984). Distinction: A social critique of the judgement of taste. Harvard University Press.

Brown, S., \& Patterson, A. (Eds.). (2003). Imagining Marketing: Art, aesthetics and the avant-garde. Routledge.

Carroll, N. (2001). Beyond aesthetics: Philosophical essays. Cambridge University Press.

Child, I. L., \& Siroto, L. (1965). Bakwele and American esthetic evaluations compared. Ethnology, 4(4), 349-360.

Cooley, C. H. (1966). Social process. New York: Scribner's.

Dealey, J. Q., \& Ward, L. F. (1905). A Text-book of Sociology. Macmillan.

Dickie, G. (1983). Perceiving Art. Visual Arts Research, 9(2), 66-70.

Elias, J. (2003). On Wings of Diesel: Spiritual Space and Religious Imagination in Pakistani Truck Decoration. RES: Anthropology and Aesthetics, (43), 187-202.

Elias, J. J. (2005). Truck decoration and religious identity: material culture and social function in pakistan. Material Religion, 1(1), 48-70.

Foster, A. W. (1989). Art and Society: Readings in the Sociology of the Arts. USA: SUNY Press. 
Freud, S. (1943). A general introduction to psychoanalysis. Garden City: Doubleday.

Heilbrun, B. (2002). Alessi: Italian design and the re-enchantment of everyday objects. Consumer behavior: A European perspective, 569-673.

Joas, H. (1992). An underestimated alternative: America and the limits of "critical theory". Symbolic Interaction, 15(3), 261-275.

Kazi, D. (1998). Decorated Trucks of Pakistan. Paper presented at the First International Convention of Asia Scholars International Institute for Asian Studies / Association for Asian Studies / Asia Committee, European Science Foundation Leeuenhorst Conference Centre, Noordwijkerhout, Netherlands. Retrieved from http://www.artnowpakistan.com/decorated-trucks-of-pakistan/

Kurt, K. (2008). Art on Wheels: The Magnificent Truck Art of Pakistan. Available: http://weburbanist.com/2008/11/22/truck-art-asia-pakistan/. Last accessed Nov 30, 2016.

Lamont, M., \& Lareau, A. (1988). Cultural capital: Allusions, gaps and glissandos in recent theoretical developments. Sociological theory, 6(2), 153-168.

Lefebvre, A. (1989). The decorative truck as a communicative device. Semiotica, 75(3-4), 215-228.

Lizardo, O., \& Skiles, S. (2008). Cultural consumption in the fine and popular arts realms. Sociology Compass, 2(2), 485-502.

Marx, M. H. (1963). Theories in contemporary psychology.

Rantala, K., \& Lehtonen, T. K. (2001). Dancing on the tightrope: Ever yday aesthetics in the practices of shopping, gym exercise and art making. European Journal of Cultural Studies, 4(1), 63-83.

Ross, E. A. (1897). Social Control. IX. Personality. The American Journal of Sociology, 3(2), 236-247.

Schroeder, J. E. (2005). Visual consumption (Vol. 4). Psychology Press.

Schroeder, J. E., \& Borgerson, J. L. (2002). Innovations in information technology: Insights from Italian renaissance art. Consumption, Markets and Culture, 5(2), 153-169.

Schulze, K. (2012). Mosques, palm trees and swords: religious symbolism in northern Nigerian lorry decorations. Annual Review of Islam in Africa, 11, 12-17.

Sorokin, P. A. (1937). Social and cultural dynamics: Fluctuation of social relationships, war, and revolution (Vol. 3). American Book Company.

Venkatesh, A., \& Meamber, L. A. (2008). The aesthetics of consumption and the consumer as an aesthetic subject. Consumption, Markets and Culture, 11(1), 45-70.

Wood, P. (1993). Modernism in dispute: Art since the forties (Vol. 4). Yale University Press. 